\title{
Factors influencing Quality Threatening Behaviour in a Big Four Accounting Firm
}

\author{
Beekes, W.A. ${ }^{\text {a }}$, Otley, D. and Ururuka, V. \\ Lancaster University Management School
}

Last updated: 3rd July 2014

Highlights: (max 85 characters including spaces)

- Evidence of dysfunctional behaviour in Big Four accounting firm in post-Enron era

- Greater emphasis on target achievement leads to dysfunctional behaviour

- An individual's place in organization's hierarchy influences behavioural responses

- Differences in behavioural responses between audit and non-audit divisions

\begin{abstract}
We investigate the determinants of employee dysfunctional behaviour, focusing on how functional area and hierarchical level affect behavioural outcomes. This is an empirical study based upon results obtained from a company based web survey in a Big Four accounting firm in the UK. Our results show dysfunctional behaviour increases when performance evaluation focuses on the achievement of pre-set targets. However such behaviours are reduced as organizational commitment, perceptions of fairness and interactions with superiors increase. Our results show that the strength of these effects differs across hierarchical levels. We also provide some preliminary evidence of differences in behavioural responses in the non-audit section of the firm. Our results confirm hierarchical level is an important contextual factor affecting the use of performance management systems.
\end{abstract}

Keywords Functional Area; Hierarchical Levels; Organizational Commitment; Employee Dysfunctional Behavior; Target Focused Evaluative Style.

${ }^{a}$ Dr Wendy Beekes [corresponding author], Department of Accounting and Finance, Management School, Lancaster University, Lancashire, LA1 4YX, UK. Email: w.beekes@lancaster.ac.uk. Tel: +44 (0) 1524593623 , Fax: +44 (0) 1524847321 


\section{Factors influencing Quality Threatening Behaviour in a Big Four Accounting Firm ${ }^{1}$}

\section{Introduction}

Targets derived from a performance management system are used to motivate performance and encourage desirable employee behaviour. According to prior research (Otley, 1987) targets should be set at an appropriate level and accepted by the individual to motivate behaviour congruent with the organization's objectives. Targets which are too difficult, or at least perceived as unattainable by the individual, are found to be counter-productive and lead to demotivated employees and/or dysfunctional behaviour to meet the target. This is particularly the case when the main focus of appraisers in regular performance appraisals is on target achievement rather than on overall effectiveness (Hopwood, 1976).

In the accounting firm literature, case study evidence (for example, Otley and Pierce, 1996b; Pierce and Sweeney, 2004) confirms that targets drive employee behaviour. Studies within organizations have found examples of very tight time budgets (i.e. providing insufficient time to complete a task with due diligence) leading to various forms of dysfunctional employee behaviour, collectively termed 'Quality Threatening Behaviour' [QTB] (Pierce and Sweeney, 2004). The use of tight time budgets is a significant issue for accounting firms as high work quality is of paramount importance (since their reputation is built upon integrity and professionalism). However the need to maintain costs within budget (as audit time is billed to the client) is also important for maintaining relationships with clients for repeat business (Power, 2003; Pierce and Sweeney, 2004). Studies in this area generally find significant QTB to meet the target as evidenced in signing off prematurely on audit checks or skipping certain steps (Pierce and Sweeney, 2004; Coram, Ng and Woodliff, 2003). They also find evidence of significant amounts of under-reported time as employees seek to complete their tasks with due diligence, but often in their own (unpaid) time (Sweeney and Pierce, 2006). This may not be dysfunctional in the short-term but may become so if the reported actuals become the standard for future periods (Bedard, Ettredge and Johnstone, 2008).

Prior research has focused on the performance management systems in place at one hierarchical level and, in the case of the accounting firm literature (for example, Pierce and

\footnotetext{
${ }^{1}$ Abbreviations used in this study are as follows: Quality Threatening Behavior (QTB)
} 
Sweeney, 2004; Sweeney and Pierce, 2006), this has been almost exclusively at the more junior levels (audit juniors and seniors). ${ }^{2}$ At present we have little evidence of how a performance management system works across the entire hierarchy in the same organization, a factor identified in Ferreira and Otley (2009). Our study of a Big Four accounting firm in the UK provides evidence on this issue. Big Four accounting firms are very hierarchical in nature and represent an ideal organization to analyse the effects of the performance management system at different hierarchical levels. This is the first study to our knowledge to pay particular attention to how organization hierarchical level affects employees' response to the performance management system and to the factors that may reduce any dysfunctional behaviour evidenced.

The consequences of dysfunctional behaviour to an accounting firm can be costly both for the individual and the firm, particularly in the post-Enron era. For example, it could lead to termination of employment for the individual, and damage to reputation and increased potential for litigation for the firm (Pierce and Sweeney, 2004, 2005). Evidence from prior studies (Alderman and Deitrick, 1982; Kelley and Seiler, 1982; Lightener, Leisenring and Winters, 1983; Kelley and Margheim, 1990; Raghunathan, 1991; Malone and Roberts, 1996; Otley and Pierce, 1996a; 1996b; Pierce and Sweeney, 2004; 2005) suggests a high incidence of dysfunctional behaviour among auditors has existed over a considerable period of time, and appeared to be increasing rather than decreasing. The Enron debacle provided significant focus upon auditors and their integrity and therefore it is of significant interest to study dysfunctional behaviours in an audit firm following this event.

Also, unlike prior studies of accounting firms, rather than focussing solely on the audit segment of the business which now represents under $40 \%$ of the Big Four accounting firms' revenues in the UK (Accountancy Age, 2013), we include the non-audit segment in our analysis which enhances the generalizability of the results of our study to other organizations. Our study therefore captures behaviour in accounting firms which has previously gone unrecognised and this is an important part of accounting firms' activities. The audit section has a cost versus quality dilemma in determining the amount of work completed; the cost is measurable but the quality of work undertaken is difficult to identify. However, this concern is less apparent in the non-audit section which operates more like other businesses in a

\footnotetext{
${ }^{2}$ This has been justified by the fact audit seniors are at the mid-point in the hierarchy and are likely to be subject to considerable pressure from superiors (Kelley and Seiler, 1982).
} 
competitive market. Therefore incentives to engage in dysfunctional behaviour are expected to be different in non-audit work. All employees who participated in this company survey are graduates and have followed a standard training route and therefore the non-audit section also provides a useful control for the results found in the audit section of the business.

This study contributes to the literature in the following ways: Firstly, by using case study evidence from responses from a company based web survey in a Big Four accounting firm we provide evidence on how targets influence employee behaviour. We specifically focus on how hierarchical level and other organizational factors such as organizational commitment, perceptions of fairness and interaction with superiors may change employee behaviour. Our analysis is more complete than prior studies as it also considers how employee characteristics (such as gender and length of time in job) make a difference to employee behaviour. Second, we show evidence of the level of dysfunctional behaviour in a Big Four accounting firm in a post-Enron era, when it may be expected that dysfunctional behaviour in accounting firms would be reduced. This study is therefore timely in that it provides evidence on employee behaviour following a period of intense scrutiny of accounting firms' activities. Thirdly, to benchmark our results from the audit section and provide some insight into results of other business areas, we provide comparative results for both the audit and non-audit sections of the business whereas prior literature has focussed upon the audit section only. Fourthly, we develop new questionnaire instruments for target-focussed appraisal style and interactive control. Finally, we adapt instruments from prior literature for this study and results confirm use of a reduced number of items for instruments from the existing literature provide reliable results.

In summary our results show that the behavioural responses differ by hierarchical level. The level of target and target focus of appraisers are both influential in employees' decision to engage in QTB, but the effect is not universal across all hierarchical levels. However, individuals with greater organizational commitment who perceive that they have been treated fairly by the organization, and have a superior who interacts with them regularly are less likely to engage in dysfunctional behaviour, although the strength of response differs by hierarchical level and by functional area. 
The remainder of the paper is organized as follows: the next section reviews the literature and develops our hypotheses. Section 3 describes the research method and data. Section 4 discusses our results and section 5 contains our conclusions.

\section{Hypothesis Development}

This study focussed on the relationship between performance management system and dysfunctional behaviour at all hierarchical levels. Following Pierce and Sweeney (2004; 2005; 2010), we use the term Quality Threatening Behaviour (QTB) to encompass a group of dysfunctional behaviours which have the potential to undermine the quality of work completed. We specifically focus upon the following QTB: (i) excessive short-term focus at the expense of long term effectiveness (Anthony and Govindarjaran, 2004); (ii) taking actions which are 'against an individual's better judgement' (Otley and Pierce, 1995); (iii) remaining in the office after hours (i.e. presenteeism); (iv) skipping necessary procedures to enable premature sign-off on a task (Otley and Pierce, 1996b); and (v) under-reporting of time on an allocated task and avoiding an unfavourable budget variance (Otley and Pierce, 1995; Sweeney and Pierce, 2006; Bedard et al. 2008).

Whilst short-term consequences of presenteeism and under-recording of time may be perceived as non-dysfunctional, there can be longer term adverse consequences. Presenteeism can result in negative consequences in terms of more tired or stressed employees in the firm (Ng, Sorensen and Feldman, 2007). It can have an adverse impact on productivity and the quality of work completed by an employee. With regard to time budgets and under-reporting of time spent on a task, Sweeney and Pierce (2006) suggest that if budgets remain 'time tight', or even are cut down in hours in future years, this could result in QTB by future auditors to meet the target time for a particular task. Other studies (e.g. Otley and Pierce, 1995; Pierce and Sweeney, 2004) use under-reported time as a separate variable and for this reason, in sensitivity analysis we discuss models which evaluate the components of QTB separately.

\subsection{Target Difficulty and QTB}

Like many organizations, accounting firms use targets to motivate their employees and maximise performance consistent with organizational goals. Prior research (for example, 
Otley, 1987) suggests more challenging targets are accompanied by greater effort and achievement, providing the employee considers the target to be achievable. However, there is an inherent problem of setting appropriate targets in accounting firms for the audit section; Whilst the engagement time and costs of auditing a client are measurable and easy to control (through time budgets i.e. budgets which provide employees a particular amount of time to carry out a task), employees' work output and quality of work is less easy to observe, making it more difficult to measure and control (Otley and Pierce, 1996a). Audit quality in such firms is of paramount importance, even over-riding commercial considerations. However, like any other profit-oriented organization, professional accounting firms need to maintain commercial viability in order to continue functioning. In trying to improve profit and maintain commercial viability, a direct conflict ensues between doing high quality work and keeping costs down by limiting chargeable time. Consequently, the pressure of the costquality conflict elicits a variety of QTB which may include under-reporting of time on audits, prematurely signing off an audit step, accepting weak client explanations, not fully investigating an accounting principle, and reducing the amount of work performed on an audit step (Pierce and Sweeney, 2004; Coram et al., 2003). Bedard et al. (2008) suggest that even if adverse variances are reported by the audit engagement team, the following year some additional hours in the budget may be allocated, but this would remain at a level insufficient to complete the task, providing incentives for QTB. Concerns regarding time allocated to clients may be less pressurized in the non-audit section of the business, although the temptation to engage in QTB to meet target outcomes is still expected to be present. Based upon prior evidence, we predict:

\section{$H_{1}$ : there is a positive association between the level of target difficulty and QTB}

\subsection{Target Focussed Performance Appraisal and QTB}

If the level of target taken as a given, the amount of emphasis placed upon the target by the appraiser in regular performance appraisals will also have implications for employee behaviour. Prior research has found that target-focussed appraisers (i.e. superiors who are concerned with target achievement at all costs) can result in greater dysfunctional behaviour (Hopwood, 1972; Otley and Pierce, 1995; Sweeney and Pierce, 2004). It would be expected that an accounting firm would be associated with tight focus on budgets and an inflexible approach to target achievement to maintain costs (Otley and Pierce, 1995; Sweeney and Pierce, 2004). If this is the case, it is a natural response to take action to meet the target if this is the main aspect appraisers find important, irrespective of the longer term implications 
of dysfunctional behaviour. Given the unobservable nature of much of the auditors' work and the problem of adequate monitoring of junior employees (Otley and Pierce, 1995), a target-focussed appraiser would likely result in audit employees exhibiting greater QTB to (apparently) meet the expected level of performance. Based upon our prior discussion, we predict:

$\mathrm{H}_{2}$ : there is a positive association between the level of target focus by superiors in performance appraisal and QTB.

\subsection{Organizational Commitment and QTB}

Employees' job satisfaction and positive feelings about the organization may be influential on the level of QTB used. As mentioned earlier, auditors' work quality is difficult to observe, hence increasing the importance of personnel and other forms of social controls (Otley and Pierce, 1996a). Therefore having some type of commitment to the organization may persuade employees to engage in less QTB than they otherwise would. Amongst audit seniors, Otley and Pierce (1996a) found lower dysfunctional behaviour where employees exhibited organizational commitment, although Malone and Roberts (1996) found no confirmatory evidence in support of this relationship. We predict an acceptance of organizational values and a desire to maintain membership of the organization to be associated with a reduced level of QTB.

$H_{3}$ : there is a negative association between the level of organizational commitment and QTB.

\subsection{Fairness in Treatment and QTB}

Employees' behaviour may also be influenced by perceptions of fairness with regard to allocated tasks, and rewards and promotions received. It is important that individuals feel that they have been treated fairly and are appropriately rewarded for their efforts. In addition it is also important that individuals perceive that they have been treated equitably relative to other colleagues in the organization (Bol, 2011). Individuals that perceive themselves to be rewarded fairly by the organization will be more satisfied in their role and are more likely to perform better (Janssen, 2001). Conversely, individuals which perceive that they have been under-rewarded may actually adjust their effort levels and engage in undesirable behaviour (Akerlof and Yellen, 1990). We would expect that greater perceived equity in treatment to be associated with a reduced level of QTB and predict:

$\mathrm{H}_{4}$ : there is a negative association between the perceived level of fairness and QTB. 


\subsection{Interactions with Superiors and QTB}

Big Four accounting firms are very hierarchical; Partners provide the overall strategic direction and they work very closely with Directors who are the next lower level in the hierarchy. Below them, Senior Managers and Managers provide guidance to the group of audit staff, termed Executives in this study. Despite this hierarchical structure, the regular review meetings with superiors may promote greater interaction between junior and senior staff than is the case in many organizations. Simons (1995) suggests interactive styles of management are important for encouraging desirable behaviour in subordinates and resolving uncertainty. Interactions with subordinates provide the opportunity for dialogue and promote greater trust between superior and subordinate. It can also engender a learning environment that values information sharing and new ideas from subordinates, and in addition it may provide support to resolve how to complete tasks with uncertainty. Such interactions and approachable styles of superiors has previously been found to be associated with reduced QTB (Otley and Pierce, 1995). We would expect that greater face-to-face interaction with and encouragement from superiors will be associated with a reduced level of dysfunctional behaviour and predict:

$H_{5}$ : there is a negative association between the level of interaction with superiors and QTB.

\subsection{Organizational Hierarchical Level}

It is probable that organization hierarchical level makes a difference in how employees respond to the performance management system, but at present there is little evidence of this from the literature. The Big Four accounting firm in our study has a very rigid hierarchy with distinct hierarchical levels. Directors and Senior Managers, for example, will have more authority to meet the targets and take the necessary actions to reach those targets, resulting in greater task uncertainty, which needs to be taken into account in performance assessment. Executives on the other hand are primarily concerned with passing their professional examinations and Managers in the organization will be acutely aware of this factor. ${ }^{3}$ In such hierarchical organizations, inevitably pressure from more senior employees to meet targets gets transmitted down the organization. Fixed fee audit contracts place pressure to get jobs

\footnotetext{
${ }^{3}$ Inevitably this limits the amount of pressure that Managers can pass down the hierarchy, placing Managers at a critical point in the hierarchy; they are responsible for meeting the targets set and typically will lead field teams on audit engagements, but will be unable to review the quality of work completed (Otley and Pierce, 1995) or substantially pass down the cost-quality pressures they face.
} 
done on time (i.e. within the allocation in the budget) and this pressure is felt throughout the organization (Carcello, Hermanson and Fenwick Huss, 1996). Otley and Pierce (1996a) discovered audit seniors were more likely to under-report time rather than ask their manager for a larger time budget, indicating managers were reluctant to change budgets and that they pass pressure down the hierarchy.

The time frame between actions taken and the realisation of the consequences of such actions are progressively longer in time frame higher up the hierarchy. This would suggest that a different type of target and differing level of target-focus in appraisers is required at different hierarchical levels, with broader focussed performance appraisal being appropriate in more complex or uncertain environments. At present we have only fragmented evidence of performance appraisal systems' impact on employees at different levels in the organizational hierarchy and little knowledge of how the same system in one organization is operational at all hierarchical levels. Given this limited prior evidence, we make no directional prediction for this hypothesis:

$H_{6}$ : there is no difference in employee dysfunctional behaviour by organization hierarchical level.

\subsection{Audit and Non-Audit Services}

The provision of audit generates less than $40 \%$ of revenues for the Big Four accounting firms and therefore the majority revenues are generated from non-audit services in the UK (Accountancy Age, 2013). Therefore omission of non-audit services in studies of accounting firms therefore overlooks a significant part of the business. Prior studies of employee dysfunctional behaviour have excluded the non-audit service part of the business, despite this functioning in a competitive market and operating similar to other organizations. This is an important omission as employees in the non-audit service are graduates and have followed a standard training route (as in audit service). In addition, they will be subject to cultural pressures and therefore have similar behavioural responses to employees in audit. However, there may be less opportunity to engage in dysfunctional behaviour as the client is the company and there may be more opportunities for the client to detect dysfunctional employee behaviour in the accounting firm. As we have no prior knowledge of how performance management systems will work in the non-audit services part of the accounting firm, we make no directional prediction for this hypothesis. We predict: 
$H_{7}$ : there is no difference in employee dysfunctional behaviour by line of service (audit or non-audit)

We also investigate whether employee characteristics (age, gender, length of time in job and length of time working for the organization) make any difference to the above relationships.

\section{Method}

\subsection{Sample and Survey Design}

We conducted our study in a regional office of a Big Four UK accounting firm; this firm is hierarchical in nature and has a substantial number of employees. Following initial design of the questionnaire, pilot studies were completed with academics and a small sample of the firm's employees. The firm employee sample included representation from all divisions (audit, consultancy and tax) to ensure the terminology used was appropriate for all divisions. The final survey was web-based as this was the firm's preferred mode of administration. The final questions used were the outcome of several drafts and meetings with the organization to ensure it was congruent with the organization's objectives and our study's goals. Working in an organization on a potentially sensitive issue resulted in re-design of the survey and constraints being placed upon us in terms of the number of items that could be used for each variable in the final survey instrument. However, this does not appear to have impacted on the usefulness of responses, as described below with relation to the Cronbach alpha for each of our measures (see Table 1). The Appendix lists, in the order that they are discussed in the paper, the survey questions and their related scales.

Rather than focus on a particular hierarchical level, our survey was specifically designed to elicit responses from employees at all levels in the organization from support staff to directors. ${ }^{4}$ The employees were invited to take part in the survey in an email invitation from the regional Chairman. The email explained the objectives of the survey and reinforced the anonymous nature of any responses received, except for the reporting of aggregate results to the firm. In addition, there was a link to the survey provided within the email. The webbased survey required a login and password to access the questionnaire which ensured that

\footnotetext{
${ }^{4}$ In discussions with the performance management section of the organization it was agreed to omit partners from the questionnaire as they were few in number and it was considered inappropriate to include them for reasons of anonymity.
} 
only respondents receiving the email invitation were able to access the survey and the integrity of the data were maintained. The survey took approximately fifteen minutes to complete with responses for each section being saved as respondents completed the survey.

\subsection{Sample Statistics}

Over 1,000 employees were sent this survey and we received 236 complete responses. This response rate is in line with that achieved by the firm when conducting its own staff survey questionnaires. Of these 236 responses, 21 were from support staff and are excluded from our analysis as support staff's time is not directly billable to clients. Table 1 shows that the remaining 215 responses included in our analysis are from a variety of hierarchical levels (89 are Associates or Executives; 60 are Managers; 52 are Senior Managers and 14 are Directors). The Associate and Executive levels (termed audit juniors and seniors respectively in prior studies) are both pre-qualification level employees and face similar incentives within the organization; their primary goal is to successfully obtain professional qualification. For this reason we treat them as the same hierarchical level, and both Executive and Associates are termed 'Executives' hereafter. The respondents were split $42 \%$ from the audit division and 58\% from the other non-audit divisions (tax and consultancy), and in terms of gender, $60 \%$ of respondents were male and $40 \%$ female, in line with the demography of the regional office.

- Table 1 -

\subsection{Definition and Measurement of Constructs}

Due to the constraints placed upon us by the organization, the length of our survey was restricted and therefore our instruments had to be adapted to suit this study. Where possible, we based our measures on instruments used in previous studies with amendments particular to this case firm. ${ }^{5}$ We also developed new measures as required (for target focus and interactive control, see below). Confirmatory factor analysis is used to test the dimensionality of our multi-item constructs to ensure they load positively on the same factor. We also use Cronbach alpha $(\alpha)$ to determine scale reliability (Cronbach, 1951).

\subsubsection{Quality Threatening Behaviour}

\footnotetext{
${ }^{5}$ When deciding to how to reduce the number of questionnaire items, we analysed the full instrument from the previous literature, removing duplicate items and for some items (e.g. for Fairness) we were asked to restate the questions in the positive form at the firm's request.
} 
We measure the incidence of QTB as the average of the responses a five item question. Respondents are invited to comment on their experiences and rate the frequency of their behaviours on a 5-point scale (scale: 1-5; from never to almost always) on the following five aspects: (i) taking short-term actions at the expense of the long-term (Anthony and Govindarjaran, 2004) [mean 2.56; S.D. 0.96], (ii) doing things which are against an individual's better judgement (Otley and Pierce, 1995) [mean 2.38; S.D. 0.86], (iii) working longer hours to indicate an individual is working hard, i.e. a specific type of presenteeism [mean 2.75; S.D. 1.12], (iv) skipping necessary procedures (Otley and Pierce, 1996b) [mean 2.17; S.D. 0.93] and (v) failing to record the full amount of time spent on a task, i.e. deliberate under-reporting of time (Otley and Pierce, 1995; Sweeney and Pierce, 2006; Bedard et al., 2008) [mean 3.13; S.D. 1.12]. The Cronbach alpha for QTB was $0.67 .^{6}$

\subsubsection{Target Difficulty}

Target difficulty was measured using an item adapted from Kenis (1979) and is similar to Kelley and Margheim (1990). Respondents were asked to rate their agreement with the statement 'I should not have too much difficulty reaching my goals' on a 7-point scale from strongly disagree to strongly agree [mean: 4.06; S.D. 1.31]. This item has been reverse coded so that higher scores are associated with greater levels of target difficulty. Under hypothesis 1, we expect Target Difficulty to be positively related to QTB.

\subsubsection{Target Focus}

The style of appraisal is based upon the extent to which appraisers rigidly use target achievement as a means of performance assessment. We develop a new instrument containing nine items to identify the construct of target focused evaluative style which examines the balance of quantitative versus qualitative information in performance evaluation, the extent of short term focus and the level of reward congruence with target achievement (see Appendix). ${ }^{7}$ Respondents were asked to record their level of agreement with these statements relating to the level of target focussed evaluative style on a 7-point scale from strongly disagree to strongly agree. Using confirmatory factor analysis we retain

\footnotetext{
${ }^{6}$ Although this is below the usual threshold, as Schmitt (1996) comments this is not necessarily an impediment to the usefulness of the measure.

${ }^{7}$ To benchmark our results with prior studies, in sensitivity analysis we use a similar definition for Target Focus as Hopwood (1972). The items included in this construct are included in the Appendix. Results from using this measure are reported in sensitivity analysis.
} 
three items for our construct which have factor loadings at or above 0.5. The three items identified are strictly focussed on the short-term orientation of the appraiser and are coded such that they are increasing in target focus of the appraiser. Target focus is then calculated as a simple average of the three items and has a Cronbach alpha of 0.81 . Under hypothesis 2 , we expect Target Focus to be positively related to QTB.

\subsubsection{Organizational Commitment}

Organizational Commitment examines the individual's commitment in terms of their concern for the organization and level of effort they are willing to put into tasks for the organization. Organizational Commitment was measured using four items with a 7-point measurement scale: strongly disagree to strongly agree. These items are based upon an adapted instrument from Mowday, Steers and Porter (1979) and Parker and Kohlmeyer (2005). Factor analysis confirmed one item did not load appropriately and so the final variable is measured as the average of three items. ${ }^{8}$ Organizational Commitment has a Cronbach alpha of 0.83 . Under hypothesis 3, we expect Organizational Commitment to be negatively related to QTB.

\subsubsection{Fairness}

Fairness measures the extent to which an individual feels treated fairly by the organization in term of allocation of tasks, rewards and promotion. Fairness was measured using five items with a 7-point measurement scale: strongly disagree to strongly agree. These items are based upon Janssen $(2001)^{9}$. All items load positively on to the same factor. Fairness is calculated as an average of the five items. The Cronbach alpha for Fairness is 0.83 . Under hypothesis 4, we expect Fairness to be negatively related to QTB.

\subsubsection{Interactive Control}

Interactive Control measures the level of face-to-face interaction with appraisers and encouragement from appraisers. This is a new instrument based upon ideas from Simons (1995), Abernethy and Brownell (1999) and Chenhall (2003). This differs from previous studies as it is measured from the perspective of subordinates in relation to their overall

\footnotetext{
${ }^{8}$ Mowday et al. (1979) use a fifteen instrument to measure Organizational commitment. Whilst we acknowledge that we use a parsimonious set of items for this concept compared with previous studies, the reliability of our construct seems unaffected. The Cronbach alpha of our instrument $(0.83)$ is very similar to the Cronbach alpha of 0.85 reported by Parker and Kohlmeyer (2005) for the full scale.

9 Janssen (2001, p.1042) uses a six item instrument to measure Fairness. In our study this was modified to five items and the wording was modified to make all statements positive, as was agreed with the accounting firm. The Cronbach alpha of our instrument 0.83 compares favourably with the 0.90 reported by Janssen (2001).
} 
formal performance evaluation. Interactive Control was measured using four items with a 7point measurement scale: strongly disagree to strongly agree. All four items load positively on to the same factor and Interactive Control is an average of all four items. The Cronbach alpha for Interactive Control is 0.86. Under hypothesis 5, we expect Interactive Control to be negatively related to QTB.

\subsubsection{Hierarchical Level and Division}

As noted earlier, we excluded Support Staff and Partner hierarchical levels from our study. Therefore four hierarchical levels are included: Executive, Manager, Senior Manager and Director. We include separate dummy variables for each hierarchical level and the Executive category is treated as the base category in our regressions which include all hierarchical levels. We also include a dummy variable to capture the division in which the individual works; Audit is coded ' 1 ' for the audit division and ' 0 ' for the tax and consultancy divisions. We have no directional hypothesis for relationship between QTB and hierarchical level, or QTB and Audit.

\subsubsection{Other variables}

We also control for the gender of respondents (Male), length of time in years employed in the role (Grade Tenure) and in the organization (Organization Tenure), and the respondent's age (Age). Male is a dummy variable coded 1 for male respondents and 0 for females. Some prior research finds males are "potentially less sensitive to the ethical implications of various issues" (Bernardi and Arnold, 1997, p. 653) although Radtke (2000) finds no significant difference between males and females. Therefore we make no prediction with regard to relationship between Male and $Q T B$, but we believe this is a necessary control in our models. We provide no directional predictions for Age, Grade Tenure or Organization Tenure.

\subsection{Regression Model}

We estimate the following regression model of QTB ${ }^{10}$ :

$$
\mathbf{Q T B}=\mathbf{X} \boldsymbol{\beta}+\mathbf{u}
$$

where:

\footnotetext{
${ }^{10}$ Our main model uses our construct for QTB which is based upon five items (see Appendix for details). In further analysis, we estimate models using the underlying components of QTB separately.
} 
$\mathrm{X}$ is a vector of explanatory variables and $\mathrm{u}$ is the error term.

Model 1 is the base model which includes the explanatory variables Target Difficulty, Target Focus, Organizational Commitment, Fairness and Interactive Control. We also control for gender (Male), Grade Tenure, Organization Tenure and Age. In addition to the variables from Model 1, Model 2 includes variables to capture the effects of hierarchical level (Manager and Senior Manager, Director) and division (Audit). Our models are estimated using Ordinary Least Squares (OLS) regression methods with standard errors robust to the presence of heteroskedasticity. Our model is initially estimated using for the complete sample including all hierarchical levels. We also estimate our model by hierarchical level separately (except for Directors as there are insufficient responses to complete a separate meaningful analysis for that hierarchical level), by division and also by gender. The results are discussed in the next section.

\section{Results}

\section{TABLE 1 XX}

Table 1 shows the descriptive statistics for variables for the full sample which includes the mean and standard deviation, minimum and maximum (both theoretical and actual). In addition, there are mean values by hierarchical level, division and gender. QTB is significantly different across different hierarchical levels ( $p$-value 0.04), with Managers responding with the greatest average level of QTB (mean: 2.72) and Directors with the lowest level of QTB (mean: 2.2). However, we find no significant difference in the level of QTB between the divisions or in terms of gender of respondents. Target Difficulty differs by hierarchical level ( $p$-value 0.01) with Directors being assigned the most challenging targets (mean: 4.71) compared with Executives (mean: 3.71). There is no significant difference across division in terms of Target Difficulty, but in an analysis of Target Difficulty and gender, it is apparent that men perceive their targets to be more challenging than women (mean of 4.22 for men compared with a mean of 3.81 for women; $p$-value $=0.03$ ). Target Focus has a mean of 2.89 and there is no statistically significant difference in Target Focus across hierarchical level, division or gender. Organizational Commitment has an average of 5.1 and this differs by hierarchical level ( $p$-value $=0.01)$; Organizational Commitment increases with hierarchical level and Directors have the greatest Organizational Commitment (mean: 6.0). There is no significant difference in Organizational Commitment by division or gender. The mean perceived level of Fairness is 4.22 and this is not significantly different by 
hierarchical level, division or gender. Interactive Control has a mean of 4.46, with Executives having the greatest level of interaction with superiors (mean 4.73).

The variable correlations are presented in Table 2. Consistent with our hypothesis, Target Difficulty and Target Focus have a positive correlation with QTB, whereas Organizational Commitment, Fairness and Interactive Control have a negative correlation with QTB. These relationships will be explored further in multi-variate analysis.

\section{TABLE 2 XX}

Table 3 shows the results from our regressions. Columns (1) and (2) report the results for all observations for models 1 and 2. Model 1 examines the main effects of the hypothesised variables, whilst model 2 adds variables for hierarchical level and division. Both models explain just over $20 \%$ of the variance in QTB. Columns (3) - (5) report the results for model 2 by hierarchical level, columns (6) and (7) report the results for model 2 by division, and columns (8) and (9) report the results for model 2 by gender. The more detailed models for subsets of the data have smaller sample sizes, and show explanatory levels varying from 13\% to $36 \%{ }^{11}$

\section{TABLE 3 XX}

\subsection{Impact of Target Level on QTB}

Recall from hypothesis 1, we expect to find a positive association between Target Difficulty and QTB. However we find no support for this for the full sample (columns 1 and 2). However regression analysis by hierarchical level shows different behaviour. We find that for Executives challenging targets are associated with less QTB (column 3), but for Managers challenging targets are associated with more QTB (column 4). Perhaps as employees reach this point in the hierarchy it becomes harder to reach the target and engaging in QTB is a coping mechanism as targets are unattainable without it. We find no significant effect for Senior Managers in our sample (column 5). There is also no significant impact of Target Difficulty on QTB by division (column 6 and 7) although females are less likely to engage in QTB in response to challenging targets (column 8).

\footnotetext{
${ }^{11}$ The explanatory power is comparable with previous studies examining QTB, although they use different instruments and variables; Otley and Pierce (1996a) report an $\mathrm{R}^{2}$ of 0.53, Malone and Roberts (1996) report an $\mathrm{R}^{2}$ of 0.17, and Pierce and Sweeney (2004) report an $\mathrm{R}^{2}$ of 0.098 .
} 


\subsection{Impact of Target Focus in Performance Appraisal on QTB}

We expect a positive association between the level of Target Focus by superiors in performance appraisal and QTB (Hypothesis 2). Our results show target focused evaluative style results in greater propensity to engage in $Q T B$, as reflected in a positive and significant coefficient on Target Focus in models 1 and 2 (columns 1 and 2). Examining each hierarchical level separately, we find the sign of Target Focus is positive across all levels, although it is only significant at the Executive level (column 3). Therefore particularly adverse effects of Target Focus occur lower down the hierarchy.

We find a significant positive association between Target Focus and QTB in both the audit and non-audit divisions. Therefore, irrespective of division, target focused evaluative style engenders dysfunctional behaviour in subordinates (columns 7 and 8). In addition, our analysis by gender finds a significant relationship for Target Focus. Both male and female employees are associated with greater QTB in response to Target Focus, but males demonstrate a greater propensity for QTB in relation to Target Focus $(0.159$ vs. 0.100$)$. This is consistent with findings from previous literature (e.g. Pierce and Sweeney, 2010) which shows females exhibit higher ethical judgement than males.

\subsection{Impact of Organizational Commitment, Fairness and Interactive Control on QTB}

We expect greater Organizational Commitment, increased perceptions of Fairness and more Interactive Control reduce the level of QTB (Hypotheses 3 - 5). Our results confirm this (columns 1 and 2). The form of the relationship for Organizational commitment is consistent across hierarchical level, division and gender. In the models estimated for Senior Managers, Audit and Females this effect is highly statistically significant (columns 5, 7 and 8). The form of the relationship for Fairness is consistent across Executives and Managers, division and gender. In addition, results show that the strength of this relationship is greatest at the Executive level in the organization (column 3). We also find a greater impact of Fairness in audit $(-0.184$ vs -0.064$)$ and for females $(-0.129$ vs -0.065$)$. In addition, greater interaction with superiors is associated with fewer QTB (hypothesis 5), but only significantly so for 
Managers and Senior Managers (columns 4 and 5), in non-audit (column 6) and for females (column 8). ${ }^{12}$

\subsection{Impact of Hierarchical Level on QTB}

We make no directional prediction for the impact of hierarchical level on the relationships studied (Hypothesis 6). In model 2 the results on the indicator variables for hierarchical level are insignificant. Nevertheless our sub-sample results have demonstrated some interesting and statistically significant differences by hierarchical level. To summarize, Executives are associated with fewer instances of QTB in response to challenging targets, but greater QTB if target-focussed performance appraisal is adopted (column 3). Managers are more likely to engage in $Q T B$ to meet challenging targets (column 4), particularly those in the audit division, as indicated by the positive and significant coefficient on Manager (column 7). In addition, Organizational Commitment appears more important at the Senior Manager level for reducing QTB (column 4). Results estimated by gender would suggest female Directors are less likely to engage in QTB (column 8). Therefore it would appear from our results that hierarchical level does affect how employees respond to performance management systems.

\subsection{Audit and Non-Audit Divisions}

We make no directional prediction for the impact of division of service on the relationships studied (Hypothesis 7). Audit is insignificant in model 2, but in the model for Managers (column 4), Audit has a significant positive coefficient. This suggests Managers in Audit undertake a greater level of $Q T B$ relative to the Non-audit division. ${ }^{13}$ We find no comparable effect for the other hierarchical levels. This perhaps is due to pressure on managers to meet the tight time budgets in Audit and the necessity to retain costs within budget to meet profit targets.

\footnotetext{
${ }^{12}$ Since Organizational Commitment, Fairness and Interactive Control are negatively associated with QTB (see Table 2), we create a new variable, Overall Equity, which is a simple average of the twelve items for Organizational Commitment, Fairness and Interactive Control. The Cronbach alpha for Overall Equity is 0.87 and there is no significant difference in Overall Equity by hierarchical level, division or gender (see Table 1). The results (not tabulated) from models using Overall Equity in place of Organizational Commitment, Fairness and Interactive Control are consistent with those reported in Table 3 and Overall Equity is negative and highly significant in all model specifications.

${ }^{13}$ For each hierarchical level in the organization, we compute a two group mean test for differences in the mean level of QTB between the audit and non-audit divisions. We find no evidence to suggest a statistically different level of QTB between the divisions at any hierarchical level: $p$-values were 0.3046 for Executives, 0.1804 for Managers, 0.8146 for Senior Managers and 0.5108 for Directors.
} 
Results by division suggest that in the Audit division, increased target focus results in greater QTB, but increased Organizational Commitment and perceptions of Fairness are very important for reducing QTB. In contrast, in the Non-Audit division, it is Organizational Commitment and Interactive Control which are important in reducing QTB. This provides some preliminary evidence that there are some subtle differences in the divisions and employee responses to the performance management system, even in the same firm with the same culture and training route.

\subsection{Control variables: Age, Gender, Grade Tenure and Organization Tenure}

Age, Gender, Grade Tenure and Organization Tenure are included as control variables, but are all insignificant in models 1 and 2 (columns 1 and 2). However, Grade Tenure is positive and significant for Executives (column 3), suggesting increased length of time in the role results in greater QTB. Perhaps this shows that Executives who have been in post for a while learn what is thought of as acceptable behaviour and what they can 'get away with' in terms of cutting corners, or alternatively that they are not going to be promoted within the organization and 'cut corners' as a consequence. Therefore as they become more experienced and are set ever increasing targets, Executives find it necessary to engage in QTB to keep meeting set targets. We find no significant effect of Grade Tenure in other sample partitions, either by division or by gender. Organization Tenure is also important for Executives and it appears a longer tenure with the organization is associated with lower QTB (column 3). Age however is positive and significant for Executives and Females suggesting older Executives and older females are more likely to engage in QTB (columns 3 and 8). These control variables are not significant in any of our other model specifications.

\subsection{Further results}

We investigate the sensitivity of our results to our measure of Target Focus. We adopt a measure comparable to Hopwood (1972) which contrasts short with long-term goals. See Appendix for details of items. Target Focus and Hopwood are positively correlated $(r=$ 0.38), see Table 2. Our results (not tabulated) are comparable with those reported in Table 3, although significance of some coefficients of interest in some sub-regressions by hierarchical level, division and gender is sensitive to the definition of appraisal style. 
In addition, we re-examine each of the five items of QTB individually. ${ }^{14}$ The results for model (2) for all hierarchical levels are shown in Table 4.

\section{Table 4 XX}

Only under-reporting of time (QTB5) is significantly positively associated with Target Difficulty (column 5, Table 4). All other elements of QTB are unaffected by the level of target assigned, inconsistent with hypothesis 1. Target Focus is positively associated with each individual QTB except for skipping procedures (QTB4, column 4, Table 4). The necessity to do a diligent job (and complete all necessary steps in an allocated task) prevails irrespective of the deadlines and focus of appraisers, as suggested by Herrbach (2001). However, for other aspects, greater focus on targets does lead to greater QTB by employees, suggesting excessive target focus leads to dysfunctional outcomes, consistent with hypothesis 2. In terms of aspects which may mitigate QTB, Organizational Commitment is effective at reducing most types of QTB; it does not significantly influence presenteeism (QTB3, column 3, Table 4), although this may be an important factor in showing the team and your superiors that you are working hard. Fairness is influential in reducing the propensity for actions against better judgment (QTB2) and fewer instances of procedures being skipped (QTB4), which suggests this is an important factor in ensuring diligence in employees work. Fairness is also an important factor in reducing presenteeism (QTB3), perhaps because employees feel less of a need to demonstrate their commitment if rewards and promotions are allocated fairly. Interactive Control significantly reduces the likelihood of bad actions and skipping of necessary procedures (QTB2 and QTB4, columns 2 and 4, Table 4).

Some differences by hierarchical level are apparent. All indicators for hierarchical level are positive and significant in models examining short-term focus (QTB1) suggesting greater short-term focus as you go up the organization hierarchy (Table 4, column 1). This is result is potentially a large concern as short-term focus is potentially very harmful for the organization, especially when it is people in more senior roles taking such actions perhaps to meet short-term incentive criteria for bonus payments. Nonetheless, we are reassured to find that Directors are less likely to engage in activities against their better judgement (QTB2,

\footnotetext{
${ }^{14}$ QTB1 is 'taking actions that enhance short term performance even though it negatively impacts on long-term performance'. QTB2 is 'having to do things you feel are against your better judgement in the course of your work'. QTB3 is 'having to stay longer hours in the office to indicate you are working hard', i.e. presenteeism. QTB4 is 'feeling it necessary to avoid or skip a required procedure'. QTB5 is 'feeling I cannot record all the time I spend on specific work, project or job assignment'.
} 
Column 2), perhaps because they are more aware of the consequences of doing so. We find that presenteeism (QTB3), the decision to skip necessary procedures (QTB4) and the underrecording time (QTB5) are not significantly associated with hierarchical level.

\subsection{Summary}

In our analysis, surprisingly we find the level of challenge in targets set is not a key driver determining QTB at all hierarchical levels; the main effects of Target Difficulty on QTB are found for Managers given their pivotal position within the organization hierarchy. Target focused evaluative style affects those lower down the organization hierarchy, and causes Executives in particular to do whatever they can to meet the desired level of performance. The employees at higher hierarchical levels seem less affected by Target Focus, perhaps because they have learnt to cope better with allocated tasks and this reduces the need to engage in QTB. Alternatively, those that progress up the hierarchy may be just the more skilled employees who did not need to engage in $Q T B$ to meet the target at the Executive level and this could explain the lower amount of QTB at higher levels in the organization. As Coram et al. (2003, p. 43) acknowledge, the incidence of QTB "does not mean that the audit opinion will be incorrect", although it does increase the probability of an inappropriate decision. Therefore firms should be concerned about the incidence of QTB. Overall our study confirms the expectation that target focused evaluative style can be unproductive and may result in undesirable behaviours in employees.

Our results also suggest Organizational Commitment, Fairness and Interactive Control are important factors which help to reduce QTB. Organizational Commitment is particularly important in the decision to engage in QTB for Senior Managers and Executives, perhaps because they are seeking to remain in the organization and be promoted to the next hierarchical level. Fairness of treatment is influential for Executives and Managers, suggesting firms may find it helpful to be more transparent in the allocation of more interesting and varied tasks, along with appropriate promotion processes and perceived equity in promotions between colleagues at similar points in their careers. Somewhat inevitably, perceptions of inequitable treatment may lead to demotivation and greater QTB. For Managers and Senior Managers, Interactive Control is important suggesting greater contact with superiors may provide the opportunity for relationship building and lower likelihood of letting the team down by engaging in QTB. These results confirm our expectation that 
different mechanisms of performance management are important at different hierarchical levels.

Focusing on the individual aspects of QTB, results show greater short-term focus (QTB1) higher up the organization hierarchy, although such short-term focussed behaviour may be mitigated by greater organizational commitment. This is consistent with the view that an individual only bears the consequences of short-term focus if they remain within the organization in the longer term. Actions which are against an individual's better judgement (QTB2) are associated with more target focussed style of performance appraisal, although this does not have a significant impact on the level of necessary procedures skipped (QTB4). Nonetheless individual's actions are more likely to be more congruent with the organization's desired outcomes and fewer procedures are expected to be skipped where there is greater organizational commitment, accompanied with greater individual perceptions of fairness in allocated tasks and promotions, combined with greater interaction between junior and senior employees. Presenteeism (QTB3) is more apparent with target-focussed appraisal styles, perhaps indicating a desire to demonstrate hard working tendencies to achieve a successful performance appraisal outcome. However, if there is greater fairness in the allocation of tasks and awarding of promotions, the necessity to engage in presenteeism declines. This may be better for ensuring work quality as employees will likely be less tired and stressed ( $\mathrm{Ng}$ et al., 2007). Under-reporting of time (QTB5) is positively associated with target difficulty and more target focussed performance appraisal styles, and only Organizational Commitment reduces the likelihood of under-reporting of time on tasks completed.

Overall, it would appear that target-focussed appraisal styles are inappropriate in Big Four accounting firms as significant QTB is evidenced in response to this. We find consistent evidence that interaction with junior employees, and perceptions of fairness and equity of treatment of employees is important at engendering good behaviour in subordinates, although the strength of this relationship differs by hierarchical level and by division. In addition, organizational commitment is important to encourage less behaviour inconsistent with organizational objectives, although again the impact of organizational commitment differs by hierarchical level.

\section{Conclusions}


Our study examines the incidence of QTB in a Big Four UK accounting firm by using a webbased questionnaire. The $Q T B$ we examine are: (i) taking actions that are short-term focussed at the expense of long-term effectiveness, (ii) having to do things against an individual's better judgement, (iii) presenteeism, (iv) feeling the need to avoid or skip a required procedure and $(\mathrm{v})$ feeling unable to record the time taken on a particular task or assignment. We investigate the link between QTB and Target Difficulty, and the influence of targetfocused performance appraisal style on QTB. The role of an individual's commitment to the organization, the level of fairness in assigned jobs and rewards, and the level of interaction with superiors on the level of $Q T B$ is also considered. In addition differences in QTB across hierarchical level, and audit and non-audit divisions of the organization are examined. This study has the advantage of including both audit and non-audit divisions of the professional firm, whereas previous studies have focussed solely on audit. Whilst the audit division is important, it is not the only revenue stream of these firms and we have little knowledge of whether the behaviour documented in prior studies is applicable to both divisions. In addition, to specifically examine the differential impact of hierarchical level we focus on all hierarchical levels in our study, which has not been done previously.

Broadly, we expect more $Q T B$ if there are more challenging targets, and also if appraisers have more target focused evaluative style in performance appraisals. In addition, we predict fewer instances of QTB if there is greater individual commitment to the organization, more perceptions of fairness of treatment in terms of promotion and allocated tasks, and more instances of face to face interactions with superiors. The relationships identified are more complicated than originally envisaged at the outset of our study and from prior work. We find that the hypothesised effects exist between Target Difficulty and QTB, and also the level of target focus of superiors and QTB, although they only apply to specific groups of employees, rather than being universal across all hierarchical levels. Similarly, the impact of organizational commitment on reducing QTB differs by hierarchical level. Interestingly the impact of interaction with juniors and perceptions of fairness and equity of treatment of employees is also important at engendering good behaviour in subordinates, although the strength of this relationship differs by hierarchical level and by division.

Due to the anonymous nature of our web-survey, we were unable to raise follow up questions with respondents. However we feel this was an important design feature to ensure the integrity of the data collected. Nonetheless, we believe our study provides important insights, 
which are generalizable to other regional offices in the Big Four accounting firm studied and other accounting firms. The results from the non-audit section provide some insight into results which may be found in organizations other sectors which are subject to greater competitive pressure, although this must be investigated further by future studies.

\section{Acknowledgements}

The authors would like to thank Chiara Demartini, Aldonio Ferreira, Jan Pfister, Kwok Tong Soo, and Mahbub Zaman for useful comments on drafts of this paper. The authors would like to acknowledge financial support for this study from the Chartered Institute of Management Accountants (CIMA Project R149 'Performance Management Systems in Action').

\section{References}

Abernethy, M.A., Brownell, P., 1999. The role of budgets in organizations facing strategic change: an exploratory study. Accounting, Organizations and Society. 24(3), 189204.

Accountancy Age, 2013. 2013 Top 50 survey of firms, available at: http://www.accountancyage.com/static/top50-this-year (last accessed 3 July 2014).

Akerlof, G.A., Yellen, J.L., 1990. The fair wage-effort hypothesis and unemployment. The Quarterly Journal of Economics. 105(2), 255-283.

Alderman, C.W., Deitrick, J.W., 1982. Auditors' perceptions of time budget pressures and premature sign offs: A replication and extension. Auditing: A Journal of Practice and Theory. 1(2), 54-68.

Anthony, R.N., Govindarajan, V., 2004. Management control systems, Boston Massachusetts, Irwin, McGraw-Hill.

Bedard, J.C., Ettredge, M.L., Johnstone, K.M., 2008. Fee pressure and the longitudinal dynamics of audit engagement budgeting and reporting. Advances in Accounting. 24(1), 32-40.

Bernardi, R.A., Arnold SR., D.F., 1997. An examination of moral development within Public Accounting by gender, staff level and firm. Contemporary Accounting Research. 14(4), 653-668.

Bol, J.C., 2011. The determinants and performance effects of managers' performance evaluation biases. The Accounting Review. 86(5), 1549-1575. 
Carcello, J.V., Hermanson, D.R., Fenwick Huss, H., 1996. Inappropriate audit partner behavior: Views of partners and senior managers. Behavioral Research in Accounting. 8(Supplement), 245-268.

Chenhall, R.H., 2003. Management control systems design within its organizational context: findings from contingency-based research and directions for the future. Accounting, Organizations and Society. 28(2-3), 127-168.

Coram, P., Ng, J., Woodliff, D., 2003. A survey of time budget pressure and reduced audit quality among Australian auditors. Australian Accounting Review. 13(1), 38-44.

Cronbach, L., 1951. Coefficient alpha and the internal structure of tests. Psychometrika. 16(3), 297-334.

Ferreira, A., Otley, D. 2009. The design and use of performance management systems: An extended framework for analysis. Management Accounting Research. 20(4), 263282.

Herrbach, O., 2001. Audit quality, auditor behaviour and the psychological contract. The European Accounting Review. 10(4), 787-802.

Hopwood, A.G., 1972. An empirical study of the role of accounting data in performance evaluation. Journal of Accounting Research. 10, 156-182.

Hopwood, A.G., 1976. Accounting and human behaviour. Prentice-Hall, Englewood Cliffs, NJ.

Janssen, O., 2001. Fairness perceptions as a moderator in the curvilinear relationships between job demands, and job performance and job satisfaction. The Academy of Management Journal. 44(5), 1039-1050.

Kelley, T., Margheim, L., 1990. The impact of time budget pressure, personality, and leadership variables on dysfunctional auditor behavior. Auditing: A Journal of Practice \& Theory. 9(2), 21-42.

Kelley, T., Seiler, R.E., 1982. Auditor Stress and Time Budgets. The CPA Journal. 52(12), 24-34.

Kenis, I., 1979. Effects of budgetary goal characteristics on managerial attitudes and performance. The Accounting Review. 54(4), 707-721.

Lightener, S.M., Leisenring, J.J. Winters, A.J., 1983. Underreporting chargeable time: its effects on client billing, future budget preparation and staff evaluation and scheduling. Journal of Accountancy. 155(1), 52-57.

Malone, C.F., Roberts, R.W., 1996. Factors associated with the incidence of reduced audit quality behaviors. Auditing: A Journal of Practice \& Theory. 15(2), 49-64. 
Mowday, R.T., Steers, R.M., Porter, L.W., 1979. The measurement of organizational commitment. Journal of Vocational Behavior. 14(2), 224-247.

Ng, T.W.H., Sorensen, K.L., Feldman, D.C, 2007. Dimensions, antecedents and consequences of workaholism: a conceptual integration and extension. Journal of Organizational Behavior. 28(1), 111-136.

Otley, D.T., 1987. Accounting control and organizational behaviour, Heinneman, London.

Otley, D.T., Pierce, B.J., 1995. The control problem in public accounting firms: An empirical study of the impact of leadership style. Accounting, Organizations and Society. 20(5), 405-420.

Otley, D. T., Pierce, B. J., 1996a. The operation of control systems in large audit firms. Auditing: A Journal of Practice \& Theory. 15(2), 65-84.

Otley, D.T., Pierce, B.J., 1996b. Auditor time budget pressure: Consequences and antecedents. Accounting, Auditing \& Accountability Journal. 9(1), 31-58.

Parker, R.J., Kohlmeyer III, J.M., 2005. Organizational justice and turnover in public accounting firms: a research note. Accounting, Organizations and Society. 30(4), 357-369.

Pierce, B. Sweeney, B., 2010. The relationship between demographic variables and ethical decision making of trainee accountants. International Journal of Auditing. 14(1), 7999.

Pierce, B., Sweeney, B., 2004. Cost-quality conflict in audit firms: An empirical investigation. European Accounting Review. 13(3), 415-441.

Pierce, B., Sweeney, B., 2005. Management control in audit firms - Partners' perspectives. Management Accounting Research. 16(3), 340-370.

Power, M.K., 2003. Auditing and the production of legitimacy. Accounting, Organizations and Society. 28(4), 379-394.

Radtke, R.R., 2000. The effects of gender and setting on accountants' ethically sensitive decisions. Journal of Business Ethics. 24(4), 299-312.

Raghunathan, B., 1991. Premature signing-off of audit procedures: an analysis. Accounting Horizons. 5(2), 71-79.

Schmitt, N., 1996. Uses and abuses of coefficient alpha. Psychological Assessment. 8(4), $350-353$.

Simons, R, 1995. Levers of Control: How managers use innovative control systems to drive strategic renewal. Harvard Business School Press, Boston. 
Sweeney, B., Pierce, B., 2006. Good hours, bad hours and auditors' defence mechanisms in audit firms. Accounting, Auditing \& Accountability Journal. 19(6), 858-892. 
Table 1: Variable Summary Statistics for the Full Sample and Sample Partitions ${ }^{\mathrm{a}}$

\begin{tabular}{|c|c|c|c|c|c|c|c|c|c|c|c|c|c|}
\hline Variable & $\begin{array}{c}\text { Theoretical } \\
\text { Range }\end{array}$ & $\begin{array}{l}\text { Actual } \\
\text { Range }\end{array}$ & $\begin{array}{c}\text { All Sa } \\
\text { Mean } \\
\mathbf{N}=\mathbf{2 1 5}\end{array}$ & $\begin{array}{l}\text { ple } \\
\text { Std. } \\
\text { Dev }\end{array}$ & $\begin{array}{c}\text { Executive } \\
\mathbf{N}=\mathbf{8 9} \\
\end{array}$ & $\begin{array}{l}\text { ean by Hieı } \\
\text { Manager } \\
\mathbf{N}=\mathbf{6 0}\end{array}$ & $\begin{array}{c}\text { Irchical level } \\
\text { Senior } \\
\text { Manager } \\
\mathrm{N}=52 \\
\end{array}$ & $\begin{array}{c}\text { Director } \\
\mathrm{N}=14\end{array}$ & $\begin{array}{c}\text { Mean by } \\
\text { Non- } \\
\text { Audit } \\
\text { N = 124 }\end{array}$ & $\begin{array}{l}\text { Pivision } \\
\text { Audit } \\
\mathbf{N}=91\end{array}$ & $\begin{array}{c}\text { Mean b } \\
\text { Female } \\
\text { N = 85 }\end{array}$ & $\begin{array}{c}\text { Male } \\
\mathbf{N}=\mathbf{1 3 0} \\
\end{array}$ & $\begin{array}{c}\text { Cronbach } \\
\alpha\end{array}$ \\
\hline QTB & $1-5$ & $1-4.6$ & 2.60 & 0.66 & 2.54 & 2.72 & 2.65 & 2.2 & 2.61 & 2.58 & 2.61 & 2.59 & 0.6676 \\
\hline Target Difficulty & $1-7$ & $1-7$ & 4.06 & 1.31 & 3.71 & 4.32 & 4.17 & 4.71 & 4.09 & 4.01 & 3.81 & 4.22 & \\
\hline Target Focus & $1-7$ & $1-7$ & 2.89 & 1.16 & 2.88 & 2.94 & 2.98 & 2.45 & 2.89 & 2.89 & 2.93 & 2.87 & 0.8064 \\
\hline Org. Commitment & $1-7$ & $1-7$ & 5.10 & 1.24 & 4.93 & 4.99 & 5.27 & 6.00 & 5.01 & 5.22 & 5.04 & 5.14 & 0.8301 \\
\hline Fairness & $1-7$ & $1-6.8$ & 4.22 & 1.17 & 4.23 & 4.19 & 4.16 & 4.59 & 4.23 & 4.22 & 4.19 & 4.24 & 0.8332 \\
\hline Interactive Control & $1-7$ & $1-6.75$ & 4.46 & 1.21 & 4.73 & 4.35 & 4.14 & 4.29 & 4.39 & 4.54 & 4.45 & 4.46 & 0.8634 \\
\hline Overall Equity & $1-7$ & $1.92-6.58$ & 4.52 & 0.94 & 4.57 & 4.44 & 4.43 & 4.84 & 4.48 & 4.57 & 4.49 & 4.54 & 0.8686 \\
\hline Grade Tenure & $1-9$ & $1-9$ & 3.01 & 2.00 & 2.27 & 3.08 & 4.13 & 3.29 & 3.39 & 2.51 & 3.25 & 2.86 & \\
\hline Org. Tenure & $1-15$ & $1-15$ & 6.16 & 4.07 & 3.57 & 5.92 & 9.31 & 11.93 & 6.23 & 6.05 & 6.13 & 6.18 & \\
\hline Age & $21-51$ & $21-51$ & 34.22 & 7.31 & 28.85 & 35.35 & 39.56 & 43.64 & 35.52 & 32.45 & 33.85 & 34.46 & \\
\hline Hopwood & $0.14-7$ & $0.31-4$ & 0.93 & 0.33 & 0.93 & 0.99 & 0.87 & 0.86 & 0.92 & 0.93 & 0.96 & 0.90 & 0.6807 \\
\hline Executive $=1$ & & & $41 \%$ & & & & & & $33 \%$ & $52 \%$ & $47 \%$ & $38 \%$ & \\
\hline Manager $=1$ & & & $28 \%$ & & & & & & $33 \%$ & $21 \%$ & $27 \%$ & $28 \%$ & \\
\hline Senior Manager $=1$ & & & $24 \%$ & & & & & & $28 \%$ & $19 \%$ & $22 \%$ & $25 \%$ & \\
\hline Director $=1$ & & & $7 \%$ & & & & & & $6 \%$ & $8 \%$ & $4 \%$ & $8 \%$ & \\
\hline Audit $=1$ & & & $42 \%$ & & $54 \%$ & $32 \%$ & $33 \%$ & $50 \%$ & & & $40 \%$ & $44 \%$ & \\
\hline Male $=1$ & & & $60 \%$ & & $55 \%$ & $62 \%$ & $63 \%$ & $79 \%$ & $59 \%$ & $63 \%$ & & & \\
\hline
\end{tabular}

${ }^{a}$ Note: Bold font indicates statistically significant difference within sample partitions (hierarchical level, division and gender) at 5\% level or better.

where: QTB is Quality Threatening Behaviour, the frequency of taking actions which could be considered quality threatening; Target Difficulty is the perceived difficulty of achieving assigned goals; Target Focus is the extent to which the assessor is focused upon targets in performance appraisal (i.e. budget constrained approach); Organizational Commitment is the level of commitment individual feels towards the organization; Fairness is the extent to which the individual feels they are treated fairly in performance appraisal and assignment of rewards, relative to others in the same role, Interactive Control is the extent to which the supervisor has interactive approach; Overall Equity is a combination of Fairness, Organizational Commitment and Interactive Control; Grade Tenure is the length of time (in years) in the current grade/organizational role; Organization Tenure is length of time (in years) employed in the organization; Age is age (in years) of individual; Hopwood is an alternative measure of Target Focus Evaluative Style based upon Hopwood (1972). Executive, Manager, Senior Manager and Director are dummy variables $=1$ if the individual is at the hierarchical level of 
Executive, Manager, Senior Manager or Director respectively and 0 otherwise; Audit is a dummy variable for division $=1$ if individual is in the audit division and 0 otherwise. Other divisions include tax and consultancy divisions; Male is a dummy variable for gender $=1$ if male and 0 if female. For further details of component measures see Appendix. 
Table 2: Variable correlations amongst continuous variables $(\mathrm{N}=215)^{\mathrm{b}}$

\begin{tabular}{|c|c|c|c|c|c|c|c|c|c|c|c|c|}
\hline & & 1 & 2 & 3 & 4 & 5 & 6 & 7 & 8 & 9 & 10 & 11 \\
\hline 1 & $Q T B$ & 1.00 & & & & & & & & & & \\
\hline 2 & Target Difficulty & 0.12 & 1.00 & & & & & & & & & \\
\hline 3 & Target Focus & 0.35 & 0.15 & 1.00 & & & & & & & & \\
\hline 4 & Org. Commitment & -0.35 & -0.12 & -0.25 & 1.00 & & & & & & & \\
\hline 5 & Fairness & -0.38 & -0.12 & -0.34 & 0.42 & 1.00 & & & & & & \\
\hline 6 & Interactive Control & -0.31 & -0.22 & -0.22 & 0.34 & 0.44 & 1.00 & & & & & \\
\hline 7 & Overall Equity & -0.45 & -0.19 & -0.35 & 0.70 & 0.85 & 0.77 & 1.00 & & & & \\
\hline 8 & Grade Tenure & 0.05 & -0.09 & 0.12 & -0.04 & -0.16 & -0.17 & -0.17 & 1.00 & & & \\
\hline 9 & Org. Tenure & -0.08 & 0.07 & -0.13 & 0.13 & 0.03 & -0.14 & 0.00 & 0.56 & 1.00 & & \\
\hline 10 & Age & 0.03 & 0.14 & 0.01 & 0.06 & -0.02 & -0.15 & -0.06 & 0.55 & 0.59 & 1.00 & \\
\hline 11 & Hopwood & 0.22 & 0.12 & 0.38 & -0.18 & -0.21 & -0.01 & -0.17 & 0.03 & -0.05 & 0.01 & 1.00 \\
\hline
\end{tabular}

${ }^{b}$ For variable definitions, see Table 1. 
Table 3: Results from Models Examining the Determinants of Quality Threatening Behaviour ${ }^{\mathrm{c}}$

\begin{tabular}{|c|c|c|c|c|c|c|c|c|c|c|}
\hline \multirow[b]{2}{*}{ Column No.: } & \multirow[b]{2}{*}{$\begin{array}{l}\text { Ex. } \\
\text { sign }\end{array}$} & \multicolumn{2}{|c|}{ All Levels } & \multicolumn{3}{|c|}{ By Hierarchical Level } & \multicolumn{2}{|c|}{ By Division } & \multicolumn{2}{|c|}{ By Gender } \\
\hline & & $\begin{array}{l}\text { All } \\
(1) \\
\end{array}$ & All & Executives & $\begin{array}{c}\text { Managers } \\
(4) \\
\end{array}$ & $\begin{array}{c}\text { Senior } \\
\text { Managers } \\
(5) \\
\end{array}$ & $\begin{array}{c}\text { Non-Audit } \\
\text { (6) }\end{array}$ & $\begin{array}{r}\text { Audit } \\
(7) \\
\end{array}$ & $\begin{array}{r}\text { Female } \\
(8) \\
\end{array}$ & $\begin{array}{r}\text { Male } \\
(9) \\
\end{array}$ \\
\hline Target Difficulty & $(+)$ & $\begin{array}{r}0.005 \\
(0.16)\end{array}$ & $\begin{array}{r}0.003 \\
(0.09)\end{array}$ & $\begin{array}{l}\mathbf{- 0 . 1 0 7} \\
(1.92)^{* *}\end{array}$ & $\begin{array}{l}\mathbf{0 . 1 5 2} \\
(3.22)^{* * *}\end{array}$ & $\begin{array}{l}-0.075 \\
(1.12)\end{array}$ & $\begin{array}{r}0.042 \\
(1.05)\end{array}$ & $\begin{array}{l}-0.065 \\
(1.00)\end{array}$ & $\begin{array}{l}\mathbf{- 0 . 0 6 0} \\
(1.33)^{*}\end{array}$ & $\begin{array}{r}0.033 \\
(0.76)\end{array}$ \\
\hline Target Focus & $(+)$ & $\begin{array}{l}\mathbf{0 . 1 2 0} \\
(3.07)^{* * *}\end{array}$ & $\begin{array}{l}\mathbf{0 . 1 1 8} \\
(2.92)^{* * *}\end{array}$ & $\begin{array}{l}0.218 \\
(3.00)^{* * *}\end{array}$ & $\begin{array}{c}0.048 \\
(0.85)\end{array}$ & $\begin{array}{c}0.104 \\
(0.91)\end{array}$ & $\begin{array}{c}\mathbf{0 . 0 7 8} \\
(1.46)^{*}\end{array}$ & $\begin{array}{c}\mathbf{0 . 1 4 2} \\
(1.98)^{* *}\end{array}$ & $\begin{array}{c}\mathbf{0 . 1 0 0} \\
(1.80)^{* *}\end{array}$ & $\begin{array}{l}0.159 \\
(2.53)^{* * *}\end{array}$ \\
\hline Org. Commitment & $(-)$ & $\begin{array}{l}\mathbf{- 0 . 0 9 5} \\
(2.49)^{* * *}\end{array}$ & $\begin{array}{l}\mathbf{- 0 . 0 9 1} \\
(2.37)^{* * *}\end{array}$ & $\begin{array}{l}\mathbf{- 0 . 0 7 3} \\
(1.51)^{*}\end{array}$ & $\begin{array}{l}-0.024 \\
(0.33)\end{array}$ & $\begin{array}{l}\mathbf{- 0 . 1 9 9} \\
(2.20)^{* *}\end{array}$ & $\begin{array}{l}\mathbf{- 0 . 0 8 5} \\
(1.58)^{*}\end{array}$ & $\begin{array}{l}\mathbf{- 0 . 1 1 1} \\
(1.98)^{* *}\end{array}$ & $\begin{array}{l}\mathbf{- 0 . 1 3 5} \\
(2.90)^{* * *}\end{array}$ & $\begin{array}{l}-0.058 \\
(0.95)\end{array}$ \\
\hline Fairness & $(-)$ & $\begin{array}{l}\mathbf{- 0 . 1 0 6} \\
(2.76)^{* * *}\end{array}$ & $\begin{array}{l}\mathbf{- 0 . 1 0 7} \\
(2.87)^{* * *}\end{array}$ & $\begin{array}{l}\mathbf{- 0 . 1 3 8} \\
(2.31)^{* *}\end{array}$ & $\begin{array}{l}\mathbf{- 0 . 1 0 1} \\
(1.57) *\end{array}$ & $\begin{array}{c}0.022 \\
(0.28)\end{array}$ & $\begin{array}{l}-0.064 \\
(1.27)\end{array}$ & $\begin{array}{l}\mathbf{- 0 . 1 8 4} \\
(3.23)^{* * *}\end{array}$ & $\begin{array}{l}\mathbf{- 0 . 1 2 9} \\
(2.10)^{* *}\end{array}$ & $\begin{array}{l}-0.065 \\
(1.21)\end{array}$ \\
\hline Interactive Control & $(-)$ & $\begin{array}{l}\mathbf{- 0 . 0 6 6} \\
(1.55)^{*}\end{array}$ & $\begin{array}{l}-\mathbf{0 . 0 6 4} \\
(1.54)^{*}\end{array}$ & $\begin{array}{l}-0.064 \\
(0.98)\end{array}$ & $\begin{array}{l}\mathbf{- 0 . 1 5 7} \\
(2.34) * *\end{array}$ & $\begin{array}{l}\mathbf{- 0 . 0 8 8} \\
(1.30)^{*}\end{array}$ & $\begin{array}{l}\mathbf{- 0 . 1 3 3} \\
(2.45)^{* * *}\end{array}$ & $\begin{array}{c}0.011 \\
(0.18)\end{array}$ & $\begin{array}{l}\mathbf{- 0 . 1 1 8} \\
(2.04)^{* *}\end{array}$ & $\begin{array}{l}-0.067 \\
(1.08)\end{array}$ \\
\hline Manager & $(?)$ & & $\begin{array}{c}0.140 \\
(1.19)\end{array}$ & & & & $\begin{array}{l}-0.063 \\
(0.42)\end{array}$ & $\begin{array}{c}0.439 \\
(2.40)^{* *}\end{array}$ & $\begin{array}{r}0.002 \\
(0.01)\end{array}$ & $\begin{array}{r}0.210 \\
(1.22)\end{array}$ \\
\hline Senior Manager & $(?)$ & & $\begin{array}{c}0.094 \\
(0.65)\end{array}$ & & & & $\begin{array}{c}0.006 \\
(0.03)\end{array}$ & $\begin{array}{c}0.204 \\
(0.88)\end{array}$ & $\begin{array}{l}-0.166 \\
(0.71)\end{array}$ & $\begin{array}{c}0.180 \\
(0.96)\end{array}$ \\
\hline Director & $(?)$ & & $\begin{array}{l}-0.208 \\
(0.94)\end{array}$ & & & & $\begin{array}{l}-0.350 \\
(1.43)\end{array}$ & $\begin{array}{c}0.074 \\
(0.20)\end{array}$ & $\begin{array}{l}\mathbf{- 0 . 6 6 2} \\
(2.42)^{* *}\end{array}$ & $\begin{array}{r}0.018 \\
(0.07)\end{array}$ \\
\hline Audit & $(?)$ & & $\begin{array}{c}0.036 \\
(0.42)\end{array}$ & $\begin{array}{l}-0.104 \\
(0.78)\end{array}$ & $\begin{array}{c}\mathbf{0 . 3 6 0} \\
(2.20)^{* *}\end{array}$ & $\begin{array}{r}0.075 \\
(0.45)\end{array}$ & & & $\begin{array}{r}0.087 \\
(0.75)\end{array}$ & $\begin{array}{l}-0.009 \\
(0.08)\end{array}$ \\
\hline Male & $(?)$ & $\begin{array}{l}-0.008 \\
(0.10)\end{array}$ & $\begin{array}{l}-0.007 \\
(0.08)\end{array}$ & $\begin{array}{l}-0.029 \\
(0.23)\end{array}$ & $\begin{array}{c}0.086 \\
(0.59)\end{array}$ & $\begin{array}{c}0.054 \\
(0.27)\end{array}$ & $\begin{array}{r}0.055 \\
(0.49)\end{array}$ & $\begin{array}{l}-0.004 \\
(0.03)\end{array}$ & & \\
\hline Grade Tenure & $(?)$ & $\begin{array}{l}-0.012 \\
(0.48)\end{array}$ & $\begin{array}{l}-0.019 \\
(0.77)\end{array}$ & $\begin{array}{c}\mathbf{0 . 0 9 0} \\
(1.80)^{*}\end{array}$ & $\begin{array}{c}0.028 \\
(0.43)\end{array}$ & $\begin{array}{l}-0.008 \\
(0.16)\end{array}$ & $\begin{array}{r}0.021 \\
(0.57)\end{array}$ & $\begin{array}{l}-0.021 \\
(0.52)\end{array}$ & $\begin{array}{l}-0.027 \\
(0.77)\end{array}$ & $\begin{array}{l}-0.014 \\
(0.36)\end{array}$ \\
\hline Org. Tenure & $(?)$ & $\begin{array}{l}-0.010 \\
(0.88)\end{array}$ & $\begin{array}{l}-0.007 \\
(0.54)\end{array}$ & $\begin{array}{l}\mathbf{- 0 . 0 6 2} \\
(1.80) *\end{array}$ & $\begin{array}{l}-0.024 \\
(0.73)\end{array}$ & $\begin{array}{l}-0.003 \\
(0.12)\end{array}$ & $\begin{array}{l}-0.025 \\
(1.43)\end{array}$ & $\begin{array}{l}-0.006 \\
(0.24)\end{array}$ & $\begin{array}{l}-0.011 \\
(0.49)\end{array}$ & $\begin{array}{l}-0.009 \\
(0.55)\end{array}$ \\
\hline Age & $(?)$ & $\begin{array}{c}0.007 \\
(1.02)\end{array}$ & $\begin{array}{c}0.007 \\
(0.85)\end{array}$ & $\begin{array}{c}\mathbf{0 . 0 2 8} \\
(2.21)^{* *}\end{array}$ & $\begin{array}{l}-0.001 \\
(0.07)\end{array}$ & $\begin{array}{l}-0.023 \\
(1.19)\end{array}$ & $\begin{array}{r}0.002 \\
(0.18)\end{array}$ & $\begin{array}{r}0.012 \\
(0.90)\end{array}$ & $\begin{array}{c}0.022 \\
(1.83)^{*}\end{array}$ & $\begin{array}{l}-0.000 \\
(0.04)\end{array}$ \\
\hline Intercept & (?) & $\begin{array}{l}3.323 \\
(9.61)^{* * * *}\end{array}$ & $\begin{array}{l}3.253 \\
(8.08) * * *\end{array}$ & $\begin{array}{l}2.839 \\
(4.81)^{* * *}\end{array}$ & $\begin{array}{l}3.059 \\
(4.58)^{* * *} \\
\end{array}$ & $\begin{array}{c}4.883 \\
(5.12) * * *\end{array}$ & $\begin{array}{l}3.513 \\
(6.61)^{* * *}\end{array}$ & $\begin{array}{l}3.305 \\
(5.95)^{* * *}\end{array}$ & $\begin{array}{c}3.738 \\
(6.67)^{* * *} \\
\end{array}$ & $\begin{array}{l}2.875 \\
(5.06)^{* * *}\end{array}$ \\
\hline
\end{tabular}




\begin{tabular}{|c|c|c|c|c|c|c|c|c|c|}
\hline$F$ & $6.94 * * *$ & $5.75 * * *$ & $13.48 * * *$ & $4.69 * * *$ & 1.65 & $4.16 * * *$ & $3.94 * * *$ & $7.42 * * *$ & $2.67 * * *$ \\
\hline Adj. $R^{2}$ & 0.22 & 0.22 & 0.35 & 0.30 & 0.13 & 0.23 & 0.23 & 0.36 & 0.13 \\
\hline$N$ & 215 & 215 & 89 & 60 & 52 & 124 & 91 & 85 & 130 \\
\hline
\end{tabular}

$* p<0.1 ; * * p<0.05 ; * * * p<0.01$ (one-tailed tests where directional prediction is made and two-tailed tests otherwise)

${ }^{c}$ Note: Models are estimated using Ordinary Least Squares regression methods with heteroskedastic robust standard errors. $t$-statistics are reported in parentheses. The models are estimated for the full sample $(N=215)$ and by Hierarchical Level, Division and Gender. Variable definitions are as in Table 1. 
Table 4: Further Results Examining the Determinants of Specific Aspects of Quality Threatening Behaviour ${ }^{\mathrm{d}}$ Dependent Variable: QTB Items $1-5$ as indicated by column heading.

\begin{tabular}{|c|c|c|c|c|c|c|}
\hline & $\begin{array}{l}\text { Ex. } \\
\text { Sign }\end{array}$ & $\begin{array}{l}\text { QTB1: Short Term } \\
\text { Focus }\end{array}$ & $\begin{array}{c}\text { QTB2: Actions Against Better } \\
\text { Judgement }\end{array}$ & $\begin{array}{c}\text { QTB3: } \\
\text { Presenteeism }\end{array}$ & $\begin{array}{l}\text { QTB4: Skipping } \\
\text { Procedures }\end{array}$ & $\begin{array}{c}\text { QTB5: Under-reporting } \\
\text { of Time }\end{array}$ \\
\hline Column No.: & & (1) & (2) & (3) & (4) & (5) \\
\hline \multirow[t]{2}{*}{ Target Difficulty } & $(+)$ & -0.036 & 0.014 & 0.003 & -0.047 & 0.080 \\
\hline & & $(0.64)$ & $(0.30)$ & $(0.05)$ & $(0.93)$ & $(1.41)^{*}$ \\
\hline \multirow[t]{2}{*}{ Target Focus } & $(+)$ & 0.096 & 0.122 & 0.155 & 0.056 & 0.160 \\
\hline & & $(1.40)^{*}$ & $(2.30)^{* *}$ & $(2.15)^{* *}$ & $(0.90)$ & $(2.38)^{* * *}$ \\
\hline \multirow[t]{2}{*}{ Org. Commitment } & $(-)$ & -0.115 & -0.092 & -0.048 & -0.110 & -0.091 \\
\hline & & $(1.78)^{* *}$ & $(1.81)^{* *}$ & $(0.72)$ & $(2.15)^{* *}$ & $(1.33)^{*}$ \\
\hline \multirow[t]{2}{*}{ Fairness } & $(-)$ & -0.081 & -0.143 & -0.162 & -0.093 & -0.055 \\
\hline & & $(1.22)$ & $(2.64)^{* * *}$ & $(2.29)^{* *}$ & $(1.69)^{* *}$ & $(0.78)$ \\
\hline \multirow{2}{*}{ Interactive control } & $(-)$ & -0.074 & -0.072 & 0.020 & -0.159 & -0.033 \\
\hline & & $(1.14)$ & $(1.45)^{*}$ & $(0.29)$ & $(2.56)^{* * *}$ & $(0.47)$ \\
\hline \multirow[t]{2}{*}{ Manager } & $(?)$ & 0.334 & 0.197 & -0.030 & -0.004 & 0.205 \\
\hline & & $(1.86)^{*}$ & (1.19) & $(0.14)$ & $(0.02)$ & $(1.02)$ \\
\hline \multirow[t]{2}{*}{ Senior Manager } & $(?)$ & 0.583 & 0.000 & 0.030 & 0.102 & -0.243 \\
\hline & & $(2.63)^{* * *}$ & $(0.00)$ & $(0.12)$ & $(0.41)$ & $(0.81)$ \\
\hline \multirow[t]{2}{*}{ Director } & $(?)$ & 0.634 & -0.545 & -0.272 & -0.391 & -0.468 \\
\hline & & $(1.87)^{*}$ & $(1.94)^{*}$ & $(0.70)$ & $(1.17)$ & $(0.99)$ \\
\hline \multirow[t]{2}{*}{ Audit } & (?) & 0.167 & 0.094 & -0.089 & 0.198 & -0.192 \\
\hline & & $(1.25)$ & $(0.78)$ & $(0.56)$ & $(1.56)$ & $(1.32)$ \\
\hline \multirow[t]{2}{*}{ Male } & $(?)$ & -0.056 & 0.002 & -0.191 & 0.357 & -0.145 \\
\hline & & $(0.43)$ & $(0.02)$ & $(1.25)$ & $(2.98)^{* * *}$ & $(0.98)$ \\
\hline \multirow[t]{2}{*}{ Grade Tenure } & $(?)$ & 0.012 & -0.010 & 0.018 & -0.042 & -0.075 \\
\hline & & $(0.28)$ & $(0.27)$ & $(0.39)$ & $(1.07)$ & (1.39) \\
\hline \multirow[t]{2}{*}{ Org. Tenure } & $(?)$ & -0.011 & 0.004 & -0.041 & 0.009 & 0.002 \\
\hline & & $(0.48)$ & $(0.22)$ & $(1.48)$ & $(0.38)$ & $(0.09)$ \\
\hline \multirow[t]{2}{*}{ Age } & $(?)$ & 0.012 & 0.004 & -0.006 & -0.003 & 0.027 \\
\hline & & $(0.92)$ & $(0.39)$ & $(0.38)$ & $(0.28)$ & $(1.82)^{*}$ \\
\hline \multirow[t]{2}{*}{ Intercept } & $(?)$ & 2.997 & 3.178 & 3.691 & 3.743 & 2.658 \\
\hline & & $(5.00)^{* * *}$ & $(5.75)^{* * *}$ & $(5.36) * * *$ & $(6.17)^{* * *}$ & $(3.90)^{* * *}$ \\
\hline$F$ & & $3.72 * * *$ & $4.66^{* * *}$ & $3.12 * * *$ & $4.97 * * *$ & $3.42 * * *$ \\
\hline Adj. $\mathrm{R}^{2}$ & & 0.13 & 0.19 & 0.09 & 0.15 & 0.09 \\
\hline$N$ & & 215 & 215 & 215 & 215 & 215 \\
\hline
\end{tabular}


$* p<0.1 ; * * p<0.05 ; * * * p<0.01$ (one-tailed tests where directional prediction is made and two-tailed tests otherwise)

${ }^{d}$ Note: Models are estimated using Ordinary Least Squares regression methods with heteroskedastic robust standard errors for all hierarchical levels. $t$-statistics are reported in parentheses. Variable definitions are as per Table 1 except for the dependent variable which comprises the five different elements of Quality Threatening Behaviour. QTB1 is 'taking actions that enhance short term performance even though it negatively impacts on longterm performance'; QTB2 is 'having to do things you feel are against your better judgement in the course of your work'; QTB3 is 'having to stay longer hours in the office to indicate you are working hard'; QTB4 is 'feeling it necessary to avoid or skip a required procedure' and QTB5 is 'feeling I cannot record all the time I spend on specific work, project or job assignment'. Further details of the underlying items of quality threatening behaviour are included in the Appendix. 


\section{APPENDIX: Relevant Questions Reproduced from Survey Questionnaire}

This appendix shows the questions used in our study for the underlying variable constructs. For each construct where we are using more than one question, we validate our inclusion of the question using confirmatory factor analysis and Cronbach alpha.

\section{Quality Threatening Behaviour (QTB)}

QTB is assessed using five measurement items which are increasing in QTB. We include a composite variable which is a simple average of the five items, as well as completing analysis for the five items individually. The items are based upon items from prior literature (Anthony and Govindarjaran, 2004; Otley and Pierce, 1995; 1996b; Sweeney and Pierce, 2006). The Cronbach alpha of QTB is 0.6676.

\begin{tabular}{|c|c|c|c|}
\hline Measurement Scale: Frequency of Behaviour $(1=$ Never, $5=$ Almost Always $)$ & Mean & Std. Dev & $\%$ Scores $>2$ \\
\hline \multicolumn{4}{|l|}{$\begin{array}{l}\text { Listed below are pressures some people in other organizations claim to have experienced in } \\
\text { their jobs. To what extent have you experienced these in your current job? }\end{array}$} \\
\hline $\begin{array}{l}\text { 1. Taking actions that enhance short-term performance of the firm even though it } \\
\text { negatively impacts long-term performance. [QTB1] }\end{array}$ & 2.56 & 0.96 & $52 \%$ \\
\hline $\begin{array}{l}\text { 2. Having to do things you feel are against your better judgement in the course of your } \\
\text { work. [QTB2] }\end{array}$ & 2.38 & 0.86 & $40 \%$ \\
\hline 3. Having to stay longer hours in the office to indicate you are working hard. [QTB3] & 2.75 & 1.12 & $58 \%$ \\
\hline
\end{tabular}

\section{Target Focus}

This instrument is developed specifically for this study to focus on the balance between quantitative and qualitative information in performance appraisal, along with target focused evaluative style, and the importance of other information in performance appraisal. We find that some of the 
items do not load in factor analysis and therefore our measure is based upon items 4-6. The first two items (4 and 5) used in our measure are reverse coded to ensure they are increasing in target focus of the appraiser. Then target focus is a simple average of the three items. The Cronbach alpha of Target Focus is 0.8064 .

\begin{tabular}{|c|c|c|c|}
\hline Measurement Scale: Strength of Agreement $(1=$ Strongly disagree, $7=$ Strongly agree $)$ & Mean & Std. Dev & $\%$ Scores $>4$ \\
\hline \multicolumn{4}{|l|}{$\begin{array}{l}\text { Thinking about your last annual performance review (even if you have not yet had an annual } \\
\text { appraisal), please indicate the extent to which you agree with the statements below: }\end{array}$} \\
\hline $\begin{array}{l}\text { * My appraiser mainly uses quantitative information (e.g. financial, time and deadline } \\
\text { targets) in evaluating my performance }\end{array}$ & 3.61 & 1.61 & $30 \%$ \\
\hline $\begin{array}{l}\text { *2. My appraiser mainly uses qualitative information (e.g. quality of work done) in } \\
\text { evaluating my performance }\end{array}$ & 4.92 & 1.49 & $65 \%$ \\
\hline $\begin{array}{l}\text { * My appraiser uses qualitative and quantitative information in equal proportions in } \\
\text { evaluating my performance }\end{array}$ & 3.73 & 1.78 & $33 \%$ \\
\hline $\begin{array}{l}\text { 4. My appraiser is more concerned with my overall performance than with not meeting } \\
\text { specific goals in the short-term. [R] }\end{array}$ & 4.89 & 1.43 & $70 \%$ \\
\hline $\begin{array}{l}\text { 5. Normally my appraiser expects me to meet my goals but accepts good reasons for any } \\
\text { shortfalls in performance. [R] }\end{array}$ & 5.00 & 1.26 & $72 \%$ \\
\hline $\begin{array}{l}\text { 6. My appraiser expects me to meet my goals and is unwilling to accept explanations for } \\
\text { any shortfalls in meeting them. }\end{array}$ & 2.57 & 1.42 & $10 \%$ \\
\hline $\begin{array}{l}\text { *. My rewards depend mainly on information other than how well I meet my specific } \\
\text { goals }\end{array}$ & 4.35 & 1.57 & $47 \%$ \\
\hline *8. My rewards depend mainly on how well I met my goals & 3.77 & 1.56 & $37 \%$ \\
\hline $\begin{array}{l}\text { *9. My rewards depend equally on how well I meet my goals and on non-goal related } \\
\text { information }\end{array}$ & 3.94 & 1.56 & $36 \%$ \\
\hline
\end{tabular}

*Questions that did not load appropriately in factor analysis. An 'R' denotes item was reverse coded in composite measure. 


\section{Organizational Commitment}

The instrument used for Organizational Commitment is based upon Mowday, Steers and Porter (1979). We find the first item does not load on to the factor appropriately and therefore organizational commitment is an average of the remaining three items. The Cronbach alpha of Organizational Commitment is 0.8301 .

\begin{tabular}{|c|c|c|c|}
\hline Measurement Scale: Strength of Agreement $(1=$ Strongly disagree, $7=$ Strongly agree $)$ & Mean & Std. Dev & $\%$ Scores $>4$ \\
\hline $\begin{array}{l}\text { *1. Within my role, I would accept almost any type of work, project or job assignment in } \\
\text { order to keep working for this organization }\end{array}$ & 3.65 & 1.77 & $34 \%$ \\
\hline $\begin{array}{l}\text { 2. I am extremely glad that I chose this organization to work for over others that I was } \\
\text { considering at the time I joined. }\end{array}$ & 5.35 & 1.31 & $76 \%$ \\
\hline 3. I really care about the future of this organization. & 5.03 & 1.52 & $71 \%$ \\
\hline $\begin{array}{l}\text { 4. I am willing to put in a great deal of effort beyond that normally expected in order to } \\
\text { help this organization be successful. }\end{array}$ & 4.92 & 1.45 & $68 \%$ \\
\hline
\end{tabular}

*Question that did not load appropriately in factor analysis

\section{Fairness}

The instrument used for Fairness is based upon Janssen (2001). All items load positively on to the same factor. Fairness is calculated as an average of the five items. The Cronbach alpha for Fairness is 0.8332 .

\begin{tabular}{|c|c|c|c|}
\hline Measurement Scale: Strength of Agreement $(1=$ Strongly disagree, $7=$ Strongly agree $)$ & Mean & Std. Dev & $\%$ Scores $>4$ \\
\hline \multicolumn{4}{|l|}{ Please indicate the extent to which you agree with the following statements. } \\
\hline 2. I give a great deal of time and attention to the organization, and this is appreciated. & 4.17 & 1.4 & $43 \%$ \\
\hline $\begin{array}{l}\text { 4. I feel I am fairly treated by my employer regarding promotion and advancement } \\
\text { opportunities. }\end{array}$ & 4.31 & 1.5 & $49 \%$ \\
\hline
\end{tabular}




\section{Interactive Control}

This is a new instrument based upon ideas from Simons (1995), Abernerthy and Brownell (1999) and Chenhall (2003). All four items load positively on to the same factor and Interactive control is calculated as an average of all four items. The Cronbach alpha for Interactive Control

is 0.8634 .

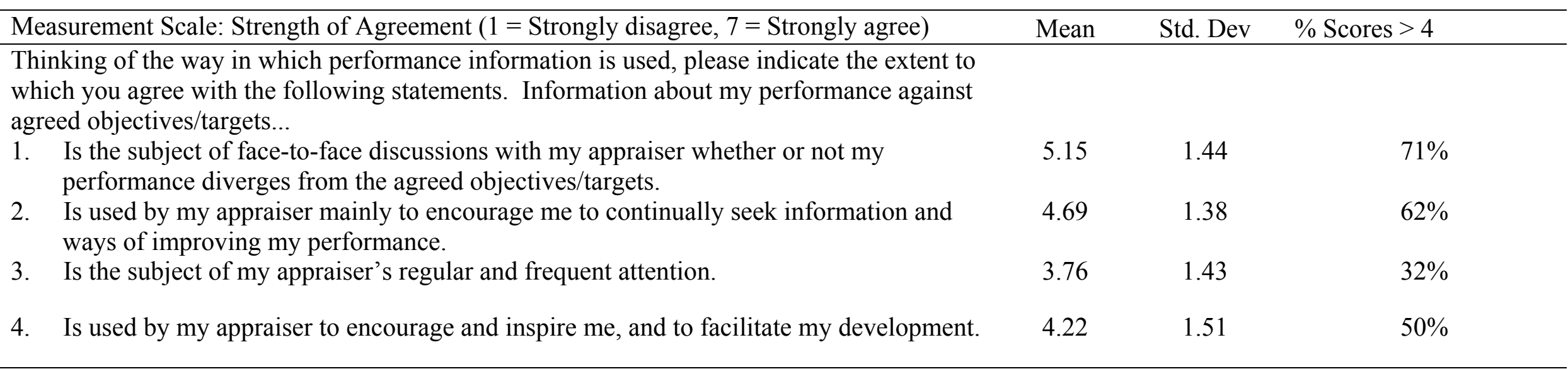

\section{Target Focus Evaluative Style Hopwood}

Our other measure of Target Focus is based on Hopwood (1972). Target Focus Hopwood compares the long and short term goals. In our study, this is measured as ([Item $3 \times 2]) /($ Item $1+$ Item 4). The Cronbach alpha for Hopwood is 0.6807.

\begin{tabular}{lll}
\hline Measurement Scale: Strength of Importance $(1=$ Not at all important, $7=$ Very Important) & Mean & Std. Dev \\
\hline Listed below are some criteria that people in other businesses have indicated to be important & & \\
in their appraiser's evaluation of their performance. Please indicate how important you & & \\
believe each criterion is in your appraiser's evaluation of your performance (even if you & &
\end{tabular}


have not yet had an annual appraisal).

1. How well I communicate and build relationships with colleagues and clients

2. How well I get along with my appraiser.

3. How well I met my goals and deadline targets.

4. The quality of my work.

5. My actions that produce long-run effectiveness rather than short-run results.

6. How much effort my appraiser perceives I put into the job.

7. How long I have been in my current position.

\#8. Are there any others? (Please list.)

\footnotetext{
${ }^{\#}$ Note: Only 28 of the 215 respondents provided an answer to this question.
} 